\title{
A Conformational Change in the Human Major Histocompatibility Complex Protein HLA-DR1 Induced by Peptide Binding ${ }^{\dagger}$
}

\author{
Jennifer A. Zarutskie, ${ }^{\ddagger}$ Aaron K. Sato, ${ }^{\ddagger}$ Mia M. Rushe, ${ }^{\ddagger}$ Iat C. Chan,,${ }^{\ddagger}$ Aleksey Lomakin, ${ }^{\S}$ George B. Benedek,${ }^{\S}$ and \\ Lawrence J. Stern*,: \\ Departments of Chemistry and Physics, Massachusetts Institute of Technology, Cambridge, Massachusetts 02139
}

Received December 28, 1998; Revised Manuscript Received March 2, 1999

\begin{abstract}
To investigate a conformational change accompanying peptide binding to class II MHC proteins, we probed the structure of a soluble version of the human class II MHC protein HLA-DR1 in empty and peptide-loaded forms. Peptide binding induced a large decrease in the effective radius of the protein as determined by gel filtration, dynamic light scattering, and analytical ultracentrifugation. It caused a substantial increase in the cooperativity of thermal denaturation and induced alterations in MHC polypeptide backbone structure as determined by circular dichroism. These changes suggest a condensation of the protein around the bound peptide. An antibody specific for $\beta 58-69$ preferentially bound the empty protein, indicating that the peptide-induced conformational change involves the $\beta$-subunit helical region. The conformational change may have important implications for the mechanisms of intracellular antigen presentation pathways.
\end{abstract}

Major histocompatibility complex $(\mathrm{MHC})^{1}$ proteins are heterodimeric cell-surface proteins that serve as restricting elements for the cell-mediated immune system. Class II MHC proteins bind peptides produced by endosomal proteolysis and present them at the cell surface for recognition by CD4+ T-cell receptors $(1,2)$. Each of the hundreds of class II allelic variants can bind a wide variety of peptides with relatively high affinity $\left(K_{\mathrm{d}} \sim 10^{-4}-10^{-6} \mathrm{M}\right)$. Crystal structures determined for six different class II MHC proteins in complex with various defined peptides $(3-10)$, along with the biochemical characterization of the peptide binding preferences of class II MHC proteins (11), have led to a good understanding of the mode of binding of high-affinity peptides. Peptides bind in an extended polyproline type IIlike conformation, placing several side chains into pockets within the site that determine the peptide sequence specificity. In HLA-DR1, a common class II MHC allele, these pockets accommodate the peptide side chains at positions $1,4,6$, and 9 (9). Many additional interactions between the peptide main chain and conserved MHC residues provide a peptide sequence-independent component to the interaction.

This work was supported by NIH Grant R01-AI38996 and a NSF REU Supplement (MCB-9506893).

* To whom correspondence should be addressed. E-mail: stern@mit.edu.

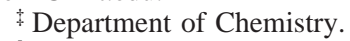

$\S$ Department of Physics.

${ }^{1}$ Abbreviations: BSA, bovine serum albumin; $C_{p}$, constant-pressure heat capacity; $\mathrm{CD}$, circular dichroism; $D_{\mathrm{T}}$, translational diffusion coefficient; DLS, dynamic light scattering; ELISA, enzyme-linked immunosorbent assay; $H_{\mathrm{v}}$, van't Hoff enthalpy; MHC, major histocompatibility (gene) complex; MW, molecular mass; PAGE, polyacrylamide gel electrophoresis; PBS, phosphate-buffered saline; $R_{\mathrm{s}}$, Stokes raduis; $s$, sedimentation coefficient; SDS, sodium dodecyl sulfate; $T_{\mathrm{m}}$, thermal denaturation midpoint temperature.
The conformations of class II MHC proteins with their bound peptides are essentially identical in the various crystal structures. However, some studies suggest that alternate conformations of the class II MHC molecule do exist under some conditions. A "floppy" species with reduced mobility in nondenaturing SDS-PAGE has been observed in vitro as an intermediate in the thermal denaturation and folding pathways for some murine class II MHC proteins $(12,13)$, and also as the predominant form at low pH (14). The "floppy" species has been observed in vivo for some class II MHC proteins produced in cells from mice lacking the class II-associated invariant chain chaperone protein $(15,16)$. In these cells, the intracellular trafficking pathway is altered, and the class II MHC proteins cannot be sorted into the endocytic compartments where they usually acquire peptide. Similar effects were observed for recombinant cell-surface class II MHC proteins expressed heterologously in cells that lack an invariant chain $(17,18)$. The altered electrophoretic mobility of the "floppy" form observed in vitro or in vivo may reflect the absence of bound peptides, or the presence of a particular set of weakly binding peptides that has been enriched by the experimental conditions.

Kinetic studies of the peptide binding reaction also have indicated alternate conformational states of class II MHC proteins. The class II peptide binding reaction exhibits rather complicated kinetic behavior with a very slow apparent forward rate constant, which has led several groups to propose a multistep peptide binding pathway in which an initial MHC-peptide complex undergoes a unimolecular change to generate the stable complex (19-21). Although these kinetic studies cannot address directly the nature or magnitude of a conformational change, the unimolecular kinetic step implies different conformations for the initial and final MHC-peptide complexes. 
For many class II MHC proteins, low $\mathrm{pH}$ favors peptide dissociation (22). Mildly acidic $\mathrm{pH}$ (4.5-6.5) decreases the SDS stability of the protein and increases its ability to bind the fluorescent probe ANS (8-amino-1-naphthalenesulfonic acid) $(23,24)$, providing evidence for a $\mathrm{pH}$-induced structural change in class II MHC proteins. Recently, direct physical comparison of empty and peptide-loaded MHC has been reported for $\mathrm{I}-\mathrm{E}^{\mathrm{k}}(25)$, where small changes in circular dichroism spectra observed at mildly acidic $\mathrm{pH}$ were interpreted as a manifestation of a peptide-dependent conformational change. In that study, the peptide-bound form exhibited a steeper thermal denaturation profile than the empty protein, which is suggestive of a looser or extended conformation in the empty protein, and indicating a possible similarity to the "floppy" species described above. Similar differences in CD spectra and thermal denaturation profiles have been observed for empty and peptide-loaded class I proteins $(26-29)$.

Taken together, these studies suggest that alternate conformations of the class II MHC protein can exist when peptide binding is absent or destabilized. A direct measurement of the extent of such conformational alteration has never been reported, however. Many previous studies which have attempted to address this issue have been complicated by the presence of physical and chemical heterogeneity in the MHC protein, and by variable occupancy of the peptide binding site with endogenous and/or uncharacterized peptides. In addition, empty class II MHC proteins produced in recombinant systems have exhibited a pronounced tendency to aggregate (30), and the presence of these aggregates complicates physical analysis of the protein. In this study, we used homogeneous, monomeric, soluble forms of empty and peptide-loaded HLA-DR1 complexes produced by expression in Escherichia coli and folding in vitro (31).

Comparing the protein in its empty state and when it is bound to several different peptides, we find that peptide binding induces a significant, definable conformational change in HLA-DR1 at neutral $\mathrm{pH}$. This conformational change has important implications for the mechanisms of intracellular antigen binding and trafficking by MHC proteins.

\section{EXPERIMENTAL PROCEDURES}

Empty HLA-DR1. The extracellular portion of HLA-DR1 was produced by expression of isolated subunits in $E$. coli inclusion bodies followed by refolding in vitro as described in ref 31. Refolded HLA-DR1 protein was recovered by immunoaffinity chromatography using a conformationspecific monoclonal antibody, and was transferred into PBS [136 mM NaP, $3 \mathrm{mM} \mathrm{KP}$, $10 \mathrm{mM} \mathrm{NaCl}, 2 \mathrm{mM} \mathrm{KCl}$, and $0.02 \%$ sodium azide ( $\mathrm{pH} 7.2$ )] containing $10 \%$ glycerol for storage at $4{ }^{\circ} \mathrm{C}$. The presence of glycerol minimized the extent of protein aggregation during storage. Glycerol and any aggregated protein that had accumulated were removed by HPLC gel filtration in PBS immediately before use. The protein concentration was measured by UV absorbance at $280 \mathrm{~nm}$ using an $\epsilon_{280}$ of $54375 \mathrm{M}^{-1} \mathrm{~cm}^{-1}$ for empty DR1.

Peptide Loading. Peptides were synthesized using solidphase Fmoc chemistry, deprotected, and purified by reverse phase chromatography using standard methods. The identity of the purified peptides was confirmed by matrix-assisted laser desorption (MALDI) mass spectrometry. Peptide-bound
DR1 complexes were prepared by incubating purified empty DR1 $\left(10^{-5}-10^{-6} \mathrm{M}\right)$ with an at least 5-fold molar excess peptide for 3 days at $37{ }^{\circ} \mathrm{C}$ in PBS with $0.02 \%$ sodium azide and a mixture of protease inhibitors (30). Alternately, peptide complexes were formed by refolding subunits in the presence of excess peptide with isolation by immunoaffinity as described above. The extent of peptide binding was routinely assayed by $10 \%$ native PAGE and by $12 \%$ SDS-PAGE with samples boiled or not in loading buffer containing 1\% SDS before loading. All of the peptide complexes described here except Min4 are resistant to SDS-induced chain dissociation at room temperature. The peptide-DR1 complexes were further purified by gel filtration or ion exchange to remove aggregates and unbound peptide. Peptide-DR1 complex concentrations were measured by UV absorbance at $280 \mathrm{~nm}$ using an $\epsilon_{280}$ of $55655 \mathrm{M}^{-1} \mathrm{~cm}^{-1}$ (Ha, Yak, and Min4; one Tyr in the peptide), $61345 \mathrm{M}^{-1} \mathrm{~cm}^{-1}$ (A2; Tyr and Trp in the peptide), or $54375 \mathrm{M}^{-1} \mathrm{~cm}^{-1}$ (Clip; no aromatic residues in the peptide).

$K_{D}$ Determination. Binding affinities were determined by a competition assay using biotinylated $\mathrm{Ha}(\mathrm{bHa})$ peptide $(\mathrm{N}$ terminal caproyl-biotinyl succinimide ester) and a sandwich ELISA using the LB3.1 antibody and streptavidin-europium essentially as described previously (32). Peptides $\left(10^{-10}\right.$ $10^{-4} \mathrm{M}$ ) were incubated with $0.5 \mathrm{nM}$ bHa and $0.5 \mathrm{nM}$ empty DR1 in PBS with $0.3 \%$ BSA and protease inhibitors at 37 ${ }^{\circ} \mathrm{C}$ for 3 days. An ELISA was used to detect the DR1-bHa complex formed in this reaction, and the $\mathrm{IC}_{50}$ values were converted to $K_{\mathrm{D}}$ using the equation $K_{\mathrm{D}}=\mathrm{IC}_{50} /[(1+[\mathrm{bHa}]) /$ $\left.K_{\mathrm{D}, \mathrm{bHa}}\right]$. The $K_{\mathrm{D} \text {, bHa }}$ was determined in a direct binding experiment by incubating $0.5 \mathrm{nM}$ empty DR1 with 2-fold dilutions of bHa $\left(10^{-11}-10^{-5} \mathrm{M}\right)$ using the ELISA to detect the DR1-bHa complex. The $K_{\mathrm{D}}$ for bHa was $14 \mathrm{nM}$, similar to a previously reported value for $\left[{ }^{125} \mathrm{I}\right] \mathrm{Ha}(33)$.

Gel Filtration. A Superdex 200 gel filtration column (Pharmacia), used at a flow rate of $0.3 \mathrm{~mL} / \mathrm{min}$ in PBS $(\mathrm{pH}$ 6.8), was calibrated using thyroglobulin (670 kDa), $\gamma$-globulin (158 kDa), ovalbumin (44 kDa), and myoglobin (17 $\mathrm{kDa}$ ) (Bio-Rad). The molecular masses of the empty and peptide-loaded DR1 were estimated from their respective elution volumes by reference to a calibration plot (34). Confidence intervals $( \pm \sigma)$ reported in Table 1 reflect the standard deviation from the mean elution volume for replicate samples and uncertainty in the nonlinear least-squares fit to the calibration plot.

Sedimentation Equilibrium. Sedimentation equilibrium experiments were performed in a Beckman XL-A analytical ultracentrifuge at 9000, 11 000, and $13000 \mathrm{rpm}$. Samples of empty DR1 and DR1-Ha were prepared for sedimentation analysis by exhaustive dialysis into PBS and concentration by centrifugal ultrafiltration. The equilibrium concentration distributions of the samples at three different concentrations $(0.1,0.25$, and $0.5 \mathrm{mg} / \mathrm{mL})$ were obtained with six measurements of absorbance $(280 \mathrm{~nm})$ at each radial position in the sample cell. The molecular mass of each sample was determined from plots of $\ln (A)$ versus $r^{2}$ (35). For comparison with experimental data, reference lines were calculated for monomeric and dimeric DR1 using an estimated value for the partial specific volume, calculated from the known sequence (see below). The conclusions realized for the oligomeric state of DR1 hold for any reasonable partial specific volume of $0.700-0.770 \mathrm{~cm}^{3} / \mathrm{g}$. Confidence inter- 
Table 1: Hydrodynamic Data

\begin{tabular}{|c|c|c|c|c|c|c|c|}
\hline \multirow[b]{2}{*}{ peptide } & \multirow[b]{2}{*}{ gel filtration MW (kDa) } & \multicolumn{3}{|c|}{ dynamic light scattering } & \multicolumn{3}{|c|}{ sedimentation velocity } \\
\hline & & $D_{\mathrm{T}}^{a}\left(\times 10^{-7} \mathrm{~cm}^{2} / \mathrm{s}\right)$ & $R_{\mathrm{s}}{ }^{b}(\AA)$ & $f l f_{0}^{c}$ & $s^{d}(10-13 s)$ & $D_{\mathrm{T}^{a}}^{a}\left(10^{-7} \mathrm{~cm}^{2} / \mathrm{s}\right)$ & $R_{\mathrm{s}}^{b}(\AA)$ \\
\hline none & $48 \pm 3$ & $6.17 \pm 1.1$ & $35 \pm 6$ & $1.3 \pm 0.2$ & $2.67 \pm 0.22$ & $5.73 \pm 0.47$ & $37.4 \pm 3.1$ \\
\hline $\mathrm{Ha}$ & $40 \pm 2$ & $7.40 \pm 1.3$ & $29 \pm 5$ & $1.1 \pm 0.2$ & $3.23 \pm 0.09$ & $6.74 \pm 0.19$ & $31.8 \pm 0.9$ \\
\hline Yak & $41 \pm 2$ & $7.76 \pm 0.4$ & $28 \pm 1$ & $1.0 \pm 0.1$ & $3.13 \pm 0.02$ & $6.57 \pm 0.05$ & $32.6 \pm 0.5$ \\
\hline $\mathrm{A} 2$ & $40 \pm 2$ & $7.40 \pm 0.4$ & $29 \pm 2$ & $1.1 \pm 0.1$ & & & \\
\hline Min4 & $39 \pm 2$ & & & & & & \\
\hline $\mathrm{Ha}$, calcd $^{e}$ & 44.6 & 7.68 & 27.9 & 1.04 & 3.68 & 7.68 & 27.9 \\
\hline
\end{tabular}

${ }^{a} D_{\mathrm{T}}$ is the translational diffusion coefficient. ${ }^{b} R_{\mathrm{S}}$ is the Stokes radius. ${ }^{c} f / f_{\mathrm{o}}$ is the frictional ratio. ${ }^{d} s$ is the sedimentation coefficient. ${ }^{e}$ Calculated values for the DR1-Ha peptide complex, from the crystal structure (9).

vals reflect the standard deviation from the mean for six replicates.

Dynamic Light Scattering (DLS). Samples for DLS were prepared by exchange into PBS and concentration by centrifugal ultrafiltration to $1 \mathrm{mg} / \mathrm{mL}$, and finally dilution to 0.5 and $0.3 \mathrm{mg} / \mathrm{mL}$. Samples in the cuvette were spun at $5000 \mathrm{rpm}$ for $60 \mathrm{~min}$ immediately prior to the measurements to remove dust. Dynamic light scattering measurements were taken at $25^{\circ} \mathrm{C}$ with an argon ion laser (Coherent Innova 90, $25 \mathrm{~W}, \lambda=488 \mathrm{~nm}$ ) at a scattering angle $\theta$ of $90^{\circ}$. Ten measurements were taken for each sample. The signal was processed by a Langley Fold model 1096 correlator, and data analysis was performed using a regularization procedure (36), modified for the analysis of the goniodyne autocorrelation function (37). The autocorrelation function was utilized to reconstruct the distribution of the scattering particles over diffusion coefficients from fluctuations in the scattering intensity of the protein solution. The values of the diffusion coefficients were corrected to $20{ }^{\circ} \mathrm{C}$. Confidence limits for these measurements reflect the standard deviation from the mean of the replicate measurements and uncertainty in temperature. The distribution of diffusion coefficients was converted into a distribution over the particles' hydrated radius $R_{\mathrm{S}}$ (shown in Figure 3) using the Stokes-Einstein equation (35):

$$
D=\frac{k T}{6 \pi \eta R_{\mathrm{s}}}
$$

where $k$ is Boltzmann's constant, $T$ the temperature (293.15 $\mathrm{K})$, and $\eta$ the viscosity of the solvent at $T(1002 \mathrm{cP})$. The frictional coefficient was determined with the equation $f=$ $k T / D$, where $D$ is the diffusion coefficient. We obtained the frictional ratio by dividing this value by the frictional coefficient expected for a spherical protein with the same molecular mass and partial specific volume (35).

Sedimentation Velocity. Sedimentation velocity experiments were performed in the same centrifuge and rotor as sedimentation equilibrium experiments, using the same sample preparation. Three different concentrations of each sample with an absorbance $(280 \mathrm{~nm})$ between 1 and 0.1 were run at $40000 \mathrm{rpm}$ at $20^{\circ} \mathrm{C}$. Scans were made every $18 \mathrm{~min}$ for $3 \mathrm{~h}$. The sedimentation coefficient, $s$, was obtained from plots of the natural logarithm of the position of the monomer boundary midpoint versus $\omega^{2} t$, where $\omega$ is the angular velocity of the rotor. The sedimentation coefficient at infinite dilution was obtained by plotting the derived sedimentation coefficients versus concentration, and extrapolating the line of best fit to a concentration of zero. Deviation from linearity was the major source of uncertainity in these values. The diffusion coefficient was obtained from the Svedberg equation (38):

$$
D=\frac{2 s T R}{M(1-v \rho)}
$$

where $s$ is the experimental sedimentation coefficient, $R$ the gas constant, $M$ the calculated molecular mass, $v$ the partial specific volume of the protein, and $\rho$ the density of the solvent $\left(0.998 \mathrm{~g} / \mathrm{cm}^{3}\right)$.

Circular Dichroism Spectroscopy and Thermal Stability. For circular dichroism (CD) analysis, purified empty DR1 and DR1-peptide complexes $(0.2-0.6 \mathrm{mg} / \mathrm{mL})$ were exchanged by dialysis into $10 \mathrm{mM}$ phosphate buffer ( $\mathrm{pH}$ 7.0) and filtered with a $0.45 \mu \mathrm{m}$ filter. CD measurements were taken at $4{ }^{\circ} \mathrm{C}$ in a $1 \mathrm{~mm}$ path length cell as described in ref 31. The expected polyproline II spectrum for 13 residues was calculated by scaling per-residue $\theta$ values of the experimental polyproline spectrum (39). Thermal denaturations were performed as described in ref 31 , monitoring the change with temperature of the CD signal at $204 \mathrm{~nm}$, which is near a negative peak in the native minus denatured difference spectrum. Smaller CD changes of the opposite sign with identical $T_{\mathrm{m}}$ values were observed for several of the complexes by monitoring at $222 \mathrm{~nm}$. We measured the dependence of the midpoint temperature on the rate of the scan, to investigate the relationship between the unfolding transition and the irreversible denaturation that occurs in the same temperature range (40). For overall scan rates of $0.5-2$ ${ }^{\circ} \mathrm{C} / \mathrm{min}$, we observed a very slight dependence, which indicated that the two-state approximation could be used at the faster scan speeds. Thermal denaturation data were fit to a seven-parameter function that describes a two-state transition $(41,42)$ :

$$
\begin{aligned}
& \theta=\left(\theta_{\mathrm{u}}+m_{\mathrm{u}} T\right)+ \\
& {\left[\frac{\left(\theta_{\mathrm{f}}-\theta_{\mathrm{u}}\right)+T\left(m_{\mathrm{f}}-m_{\mathrm{u}}\right)}{1+\exp \left[\frac{\Delta H}{R T}+\frac{\Delta C_{p}}{R}\left(\frac{T_{\mathrm{m}}}{T}-1+\ln \frac{T}{T_{\mathrm{m}}}\right)\right]}\right]}
\end{aligned}
$$

where $\theta_{\mathrm{u}}$ and $m_{\mathrm{u}}$ are the slope and $y$-intercept of the unfolded state baseline, respectively, $\theta_{\mathrm{f}}$ and $m_{\mathrm{f}}$ are the slope and $y$-intercept of the folded state baseline, respectively, $T_{\mathrm{m}}$ is the midpoint of the transition (where $\Delta G=0$ ), $\Delta C_{p}$ is the heat capacity change upon unfolding (assumed to be independent of temperature), and $\Delta H$ is the enthalpy of unfolding at the $T_{\mathrm{m}}$. For plots of DR1-A2 and DR1-Clip, few postmelt data points were available due to the high temperature of the transition. $T_{\mathrm{m}}$ values for these complexes 
could not be determined accurately and are reported as $>90$ ${ }^{\circ} \mathrm{C}$. All $T_{\mathrm{m}}$ values were verified by first-derivative analysis. Thermodynamic values derived in this analysis are likely to be dependent upon the concentration at which the equilibrium is measured, and thus only hold for the concentration ranges that were tested.

Hydrodynamic Parameters Calculated for the DRI-Ha Crystalline Structure. The partial specific volume of DR1Ha was calculated as the weighted average of the partial specific volumes of the amino acids composing DR1-Ha (43). The hydrated volume of DR1-Ha was calculated using the equation (35)

$$
V_{\mathrm{H}}=\frac{M_{\mathrm{w}} \mathrm{psv}}{N}+\left(\text { hyd }_{\text {protein }}\right)\left(\rho_{\text {water }}\right)
$$

where $M_{\mathrm{w}}$ is the molecular mass of the protein, psv is the partial specific volume $\left(0.736 \mathrm{~cm}^{3} / \mathrm{g}\right)$, hyd $\mathrm{drotein}_{\text {in }}$ is the estimated extent of hydration of the protein $(0.35 \mathrm{~g}$ of water $/ \mathrm{g}$ of protein), $\rho_{\text {water }}$ is the density of water at $20{ }^{\circ} \mathrm{C}(0.998$ $\left.\mathrm{g} / \mathrm{cm}^{3}\right)$, and $N$ is Avogadro's number. The Stokes radius, $R_{\mathrm{s}}$, was calculated using the hydrated volume, $V_{\mathrm{H}}$ :

$$
R_{\mathrm{s}}=\left(\frac{3 V_{\mathrm{H}}}{4 \pi}\right)^{1 / 3}\left(\frac{f}{f_{\mathrm{o}}}\right)
$$

where $f \mid f_{\mathrm{o}}$ is the frictional coefficient, a measure of how much the protein's shape deviates from a sphere. From the DR1Ha crystal structure, the protein can be approximated as a prolate ellipsoid with a $76 \AA$ major axis and a $38 \AA$ minor axis, for an axial ratio $p$ of $\sim 2$. The frictional coefficient was calculated as follows (35):

$$
\frac{f}{f_{\mathrm{o}}}=\frac{\left(p^{2}-1\right)^{1 / 2}}{p^{1 / 3}\left[p+\left(p^{2}-1\right)^{1 / 2}\right]}
$$

Using the calculated frictional coefficient (1.044) and $R_{\mathrm{o}}$ $\left(26.8 \AA\right.$ ), the Stokes radius $R_{\mathrm{S}}$ was calculated to be $27.9 \AA$. The diffusion coefficient of DR1-Ha was calculated using the Stokes-Einstein equation (described above) to give a predicted value of $7.68 \times 10^{-7} \mathrm{~cm}^{2} / \mathrm{s}$ at $20{ }^{\circ} \mathrm{C}$, and the sedimentation coefficient was calculated using the Svedberg equation (described above) to give a predicted value of 3.68 $\times 10^{-13} \mathrm{~s}$ at $20^{\circ} \mathrm{C}$.

ELISA. Antibody binding specificity was measured using a sandwich ELISA. Monoclonal antibody KL295 (44) was used at a concentration of $10 \mu \mathrm{g} / \mathrm{mL}$ to coat a $96-w e l l$ polystyrene microtiter plate by incubating overnight at $4{ }^{\circ} \mathrm{C}$. The plate was blocked with 3\% BSA in PBS with $0.02 \%$ sodium azide and washed with PBS with $0.05 \%$ Triton X-100 (PBST). Quadruplicate 2-fold dilutions of DR1 from 1 to $300 \mathrm{nM}$ in PBST were added and allowed to bind to the plate for $30 \mathrm{~min}$ at $37^{\circ} \mathrm{C}$, and the plates were washed five times with PBST. For Min 4 samples, $100 \mu \mathrm{M}$ free peptide was added to the incubations to prevent dissociation. The amount of bound DR1 was detected by sequential incubations with rabbit anti-DR polyclonal antibody, goat anti-rabbit peroxidase conjugate, and ABTS (405 nm) as described previously (30).

\section{RESULTS}

We used a soluble recombinant form of the protein produced by expressing DR1 $\alpha$ - and $\beta$-subunits separately

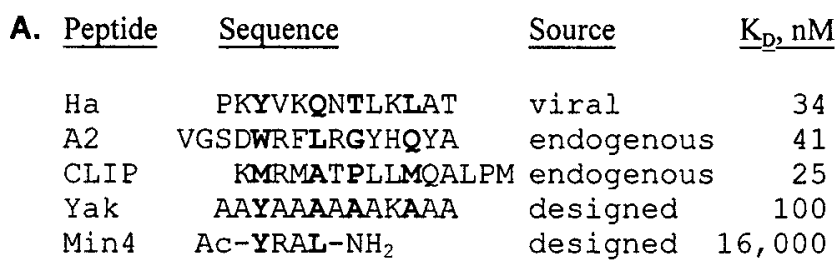

B.
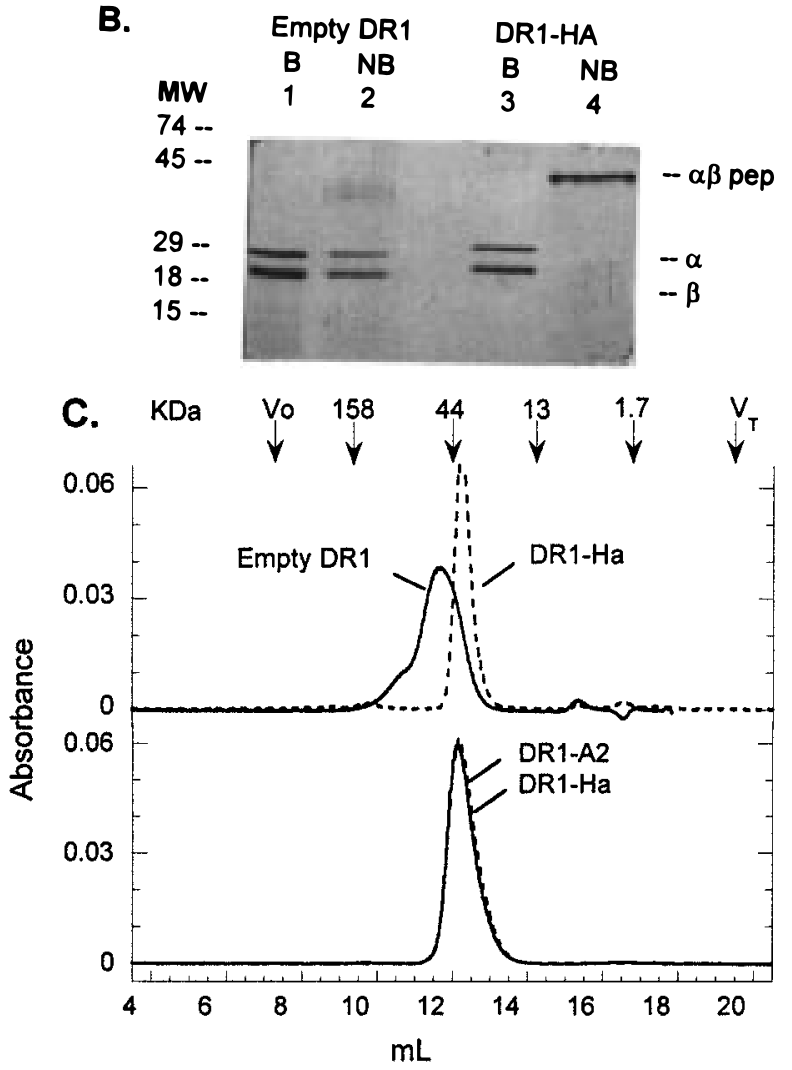

FIGURE 1: Empty and peptide-loaded DR1. (A) The sequences and experimental dissociation constants of the peptides used in this study. (B) SDS-PAGE with samples boiled (B) or not boiled (NB) before loading. Empty DR1 produced by folding in vitro subunits produced in $E$. coli is sensitive to SDS-induced $\alpha \beta$ dissocation (lanes 1 and 2), while peptide-bound DR1-Ha is resistant (lanes 3 and 4). Protein was detected with Commassie brilliant blue. (C) Gel filtration of empty DR1 and peptide complexes. The elution profile of empty DR1 is distinct from that for DR1-Ha or DR1A2, exhibiting a broader profile with a slightly larger apparent size. All proteins are substantially free of large-molecular mass aggregates. The elution position and molecular mass of protein standards shown above traces, with void volume $V_{\mathrm{o}}$ and total included volume $V_{\mathrm{T}}$ indicated.

in E. coli inclusion bodies and subsequently folding the subunits together in vitro (31). The folded material is free of contaminating proteins and peptides and is fully active in binding antigenic peptides (Figure 1A), as indicated by complete resistance to SDS-induced chain dissociation after peptide loading (DR1-Ha, Figure 1B). Importantly, the empty DR1 can be prepared free of aggregated protein, as shown by gel filtration chromatography (Figure 1C). The extent of aggregation appears to have been reduced in our system by folding and storage of the empty protein at a reduced temperature $\left(4{ }^{\circ} \mathrm{C}\right)$ and in the presence of $10 \%$ glycerol (see Experimental Procedures for details). Immediately before each measurement, we removed the glycerol, and any aggregates that had formed during storage, by gel filtration. Analytical gel filtration performed before and 


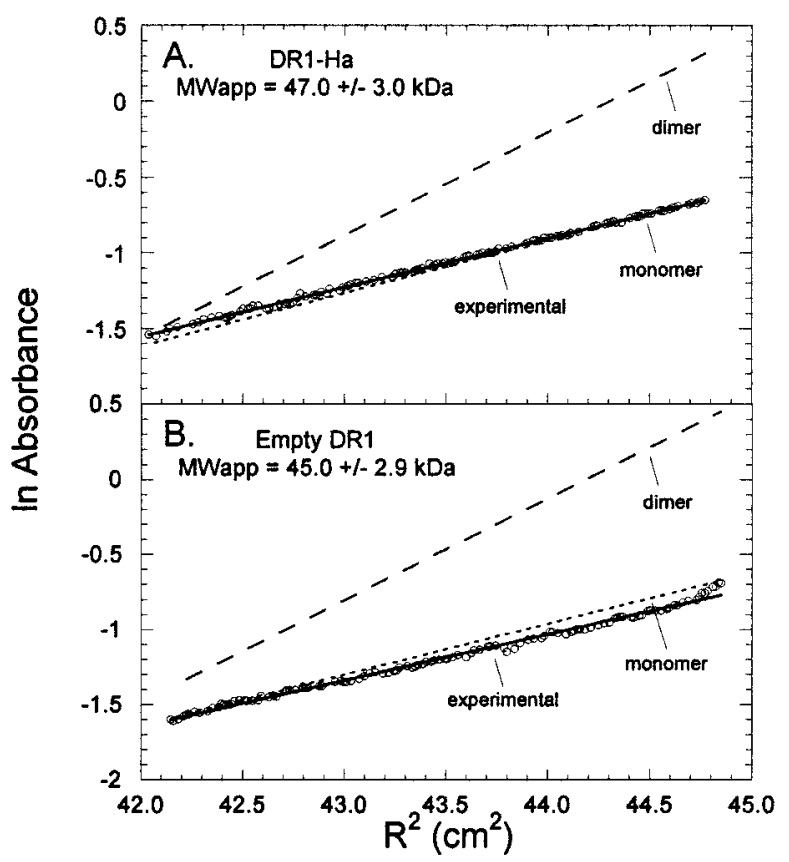

FIGURE 2: Sedimentation equilibrium indicates that both empty and peptide-loaded DR1 are monomeric: (A) DR1 loaded with Ha peptide and (B) empty DR1. Open circles show plots of $\ln (A)$ vs the square of the radial position in the sedimentation cell in square centimeters. Lines show the fit to the points (solid) as well as predicted slopes for monomeric (short dashes) and dimeric (long dashes) HLA-DR1. These data were obtained at $0.3 \mathrm{mg} / \mathrm{mL}$ and $11000 \mathrm{rpm}$, but identical sedimentation behavior was observed from 0.5 to $0.1 \mathrm{mg} / \mathrm{mL}$ and from 9000 to $13000 \mathrm{rpm}$. See Experimental Procedures for details.

after each analysis indicated no aggregate formation during any of the experimental procedures described herein.

In our refolding studies (31), we observed a consistent difference in the elution volume of empty DR1 and peptideloaded DR1 after folding and purification (Figure 1C). Although empty DR1 and peptide-loaded DR1 have essentially the same molecular mass, the empty protein exhibited an apparent molecular mass of approximately 60 $\mathrm{kDa}$, compared with $\sim 50 \mathrm{kDa}$ for the peptide-bound form. This difference was observed for complexes with peptides with different sequences, with affinities that vary more than 1000-fold (Figure 1A), including antigenic peptide Ha from influenza virus hemagglutinin (33), endogenous peptides A2 from HLA-A2 (45), and Clip from the class II-associated invariant chain (45), the minimal, tight-binding polyalaninebased peptide Yak (46), and the $\mathrm{N}$ - and C-protected tetrapeptide Ac-YRAL- $\mathrm{NH}_{2}$ (Min4), which is the shortest peptide that we have observed to bind to HLA-DR1 with measurable affinity (Figure 1A).

Because of the tendency of empty DR1 to aggregate, we investigated the possibility that its anomalous gel filtration behavior was due to it being an $(\alpha \beta)_{2}$ dimer or other higherorder oligomer. Sedimentation equilibrium analysis can provide information about solute mass independent of shape or other hydrodynamic properties, and we performed such experiments on empty DR1 and the peptide complex DR1Ha (Figure 2). The sedimentation behaviors of both empty DR1 and DR1-Ha were consistent with the molecular mass of the monomeric $\alpha \beta$ complex (Figure 2, dotted line), over a range of concentrations that span those used in the other experiments described here. In both cases, the $(\alpha \beta)_{2}$ dimer

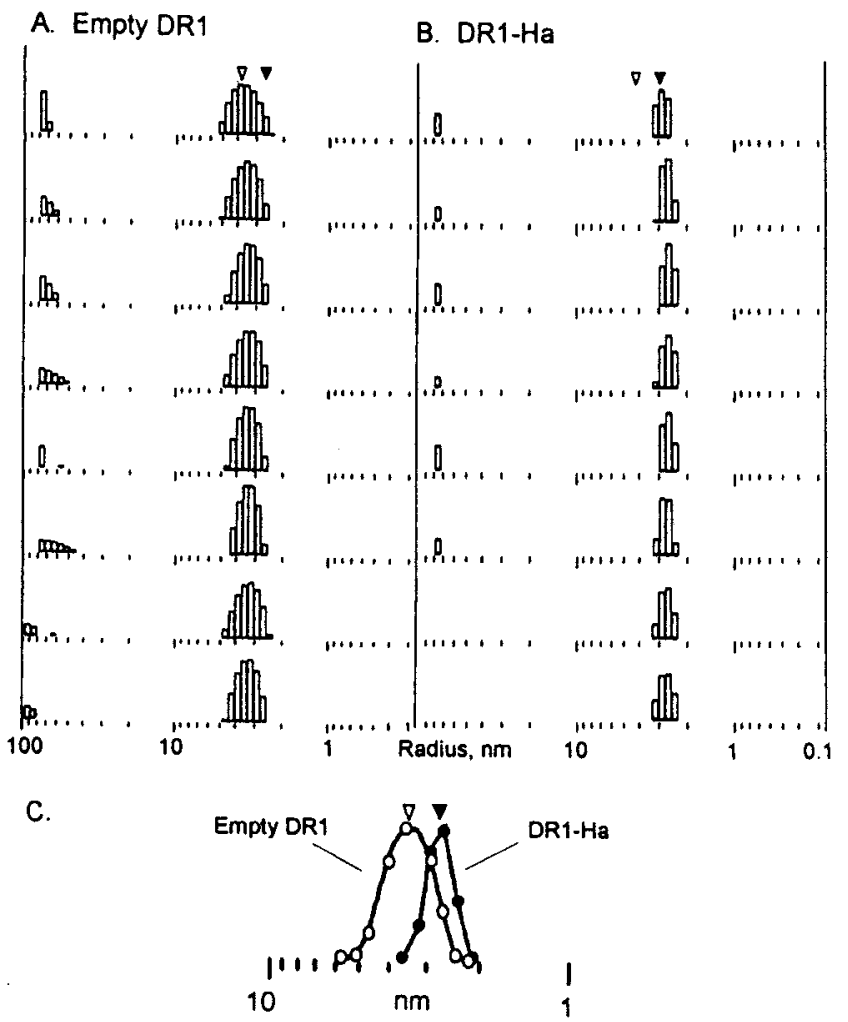

FIGURE 3: Dynamic light scattering results indicating a larger hydrodynamic radius for empty compared to peptide-loaded DR1: (A) empty DR1 and (B) DR1 loaded with Ha peptide. Histograms show the distribution of species with a hydrated radius of $0.3-$ $100 \mathrm{~nm}$. Bars between 1 and $10 \mathrm{~nm}$ correspond to macromolecular species; bars at $\sim 100 \mathrm{~nm}$ are dust or other large particles. (C) Average distributions for empty DR1 (O) and DR1-Ha (O). Open and solid arrowheads above each plot denote the average hydrated radius for empty DR1 ( $r=3.47 \pm 0.62 \mathrm{~nm}$, dashed line) and for the Ha peptide complex $(r=2.90 \pm 0.53 \mathrm{~nm}$, solid line $)$, respectively. Data are shown for $1 \mathrm{mg} / \mathrm{mL}$ and are representative for concentrations as low as $0.3 \mathrm{mg} / \mathrm{mL}$.

(Figure 2, dashed line) and higher-order oligomers could be excluded. The extracted values for the molecular masses of empty DR1 $(45.0 \pm 2.9 \mathrm{kDa})$ and DR1-Ha $(47.0 \pm 3.0$ $\mathrm{kDa}$ ) are close to the calculated monomeric values of 43.2 $\mathrm{kDa}$ for the nonhydrated empty protein and $44.6 \mathrm{kDa}$ for the Ha peptide complex (31).

To confirm that the difference in gel filtration behavior of empty and peptide-bound DR1 was due to actual differences in molecular sizes and not to differences in interactions with the gel filtration matrix, we performed dynamic light scattering (DLS) experiments. Dynamic light scattering provides a direct measure of the translational diffusion coefficient, which can be converted to an effective hydrodynamic radius for the hydrated particle. DLS experiments indicated an effective hydrated radius for empty DR1 that was significantly larger than that for DR1-Ha (Figure 3). We observed similar results for DR1 complexes with other peptides (Table 1). In each case, the observed hydrodynamic radius for the DR 1 - peptide complexes was $\sim 5 \AA$ smaller than that for the empty protein (Table 1). The results are consistent with those observed by gel filtration. Thus, we conclude that the empty and peptide-loaded forms in fact do exhibit different hydrodynamic behaviors, with the peptide-loaded form having a smaller apparent hydrodynamic radius. The peptide-loaded form is heavier than the empty 


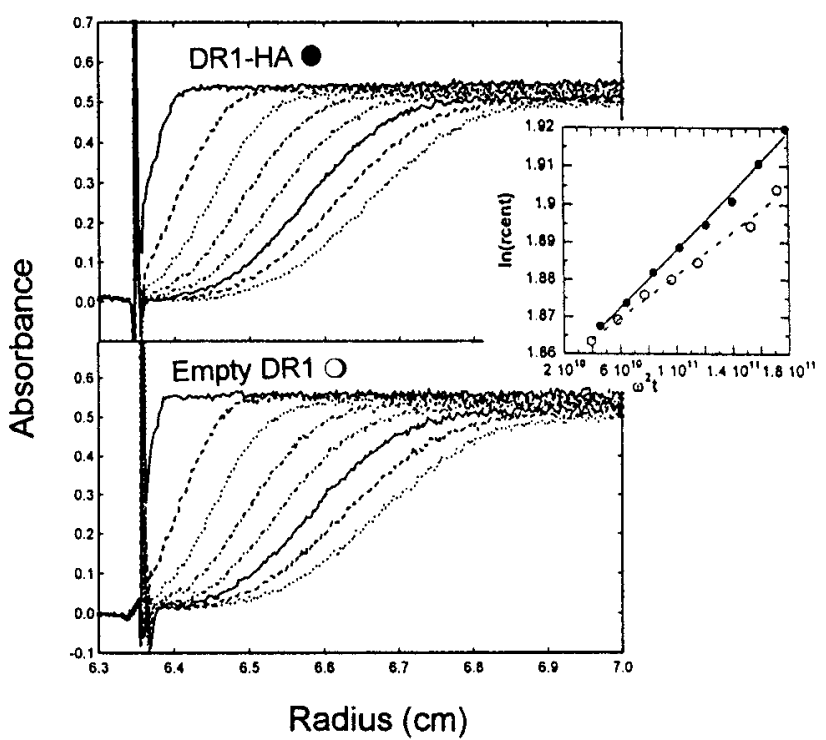

FIGURE 4: Sedimentation velocity of empty and peptide-loaded DR1. Plots of absorbance vs radial position show the distribution of protein in the centrifugation cell at 18 min intervals, 0 to 160 min (from left to right): (top) DR1-Ha, (bottom) empty DR1, and (inset) replot of centroid (inflection) position vs $\omega^{2} t$. The slope of this line provides the sedimentation coefficient, which was significantly larger for DR $1-\mathrm{Ha}(3.23 \pm 0.09 \mathrm{~S}$, black symbols) than for empty DR1 (2.67 $\pm 0.22 \mathrm{~S}$, white symbols).

protein and thus would be expected to diffuse slightly more slowly; in fact, it diffuses more quickly and must have a shape different from that of the empty form.

For further confirmation of a shape change, we performed a sedimentation velocity analysis, which probes both mass and shape (Figure 4). The empty DR1 $(2.67 \pm 0.22 \mathrm{~S}) \mathrm{did}$ not sediment as quickly as the DR1-Ha complex (3.23 \pm $0.09 \mathrm{~S})$. The same behavior was observed for the DR1Yak complex (3.13S \pm 0.02 S) (Table 1). Diffusion coefficients were estimated from the sedimentation coefficients using the Svedberg equation (see Experimental Procedures) and yielded a hydrodynamic radius of $37.4 \AA$ for empty DR1, again significantly larger than those for DR1-Ha (31.8 $\AA$ ) and DR1-Yak (32.6 ̊) (Table 1).

The slower diffusion rate of empty DR1 indicates that it experiences more frictional resistance upon moving through the solution than does the peptide-loaded form. This resistance can be described by the frictional ratio, $f / f_{\mathrm{o}}$, which relates the experimental frictional coefficient to that expected for a spherical protein with the same mass and volume. The frictional ratio of empty DR1 is 1.3 (calculated from DLS data), while the frictional ratios of the peptide-loaded forms were significantly smaller, 1.0-1.1 (Table 1 ). This indicates a definite difference in the shape between the two forms of the protein, since their masses are similar and cannot account for the differences in diffusion behavior.

Three-dimensional structures have been determined by X-ray crystallography for the DR1-Ha $(9,10)$ and DR1A2 (5) peptide complexes, as well as for the closely related DR3 analogue of the DR1-Clip complex (8). These structures permit the calculation of hydrodynamic parameters (see Experimental Procedures for details). Calculated parameters for DR1-Ha are listed in Table 1. The hydrodynamic values calculated from the crystal structures agree with the experimental values for the peptide complexes but not with those for the empty protein. This suggests that the shape of the complexes in solution is similar to that of the crystalline complex, and that the conformation of the empty protein is altered.

To investigate if alterations in DR1 secondary structure accompany the peptide-induced hydrodynamic change, we used far-UV circular dichroism (CD) spectroscopy to probe the conformation of the polypeptide backbone. The $\mathrm{CD}$ spectrum of empty DR1 [Figure 5A (O)] was altered relative to that of the DR1-Ha peptide complex $(\mathbf{)}$, exhibiting decreased intensity both in the broad negative band centered at $210-220 \mathrm{~nm}$ and in the positive band at shorter wavelengths. Similar spectral changes have been observed for a murine class II MHC allele, but only at low $\mathrm{pH}$ or elevated temperature (25). These alterations are distinct from those that accompany protein denaturation (Figure 5A, dashed line). The spectral changes, as well as the empty minus peptide-loaded difference spectra, were similar for other peptide complexes (Figure 5B,C). Difference spectra between different peptide complexes were essentially featureless (Figure 5D). As revealed in the crystal structures, peptides are bound to class II MHC proteins in an unusual polyproline II-like conformation that might be expected to contribute significantly to the circular dichroism spectrum. Although far-UV CD spectra cannot be predicted exactly for unusual conformations, we can approximate the expected peptide contribution to the spectrum as that of a corresponding length of polyproline in the type II conformation, for which experimental data are available (39). This predicted peptide contribution to the overall CD spectrum (shown with greatly expanded scale as a dashed line in Figure 5C) is much smaller than and its sign opposite from that of the observed changes that occur with peptide binding. Thus, the spectral signal from the peptide itself cannot explain the polypeptide backbone changes observed upon peptide binding.

Thermodynamic analysis can provide information about the nature of protein structural changes. We observed differences in thermodynamic parameters between the empty and peptide-loaded DR1, as measured by thermal denaturation experiments. MHC thermal denaturation is in general irreversible, in that completely denatured protein will not spontaneously refold upon cooling $(25-29,31)$. However, in our experiments, the melting temperature and extracted thermodynamic values were essentially independent of scan rate, indicating that these values reflect the underlying reversible folding transition and not a subsequent irreversible denaturation step (40). Empty DR1 exhibited a cooperative thermal denaturation with a midpoint $T_{\mathrm{m}}$ of $\sim 70{ }^{\circ} \mathrm{C}$ (Figure 6). Bound peptide increased the stability of DR1 by 3 to $>20{ }^{\circ} \mathrm{C}$ for the various peptide complexes (Table 2), in general proportion to the affinity of the bound peptide (Figure 1A). The stability increase is expected given the large number of peptide-MHC interactions observed in the crystal structures. Unexpectedly, peptide binding also increased the coopera-

tivity of denaturation, which can be observed as an increased slope in the $\theta$ versus temperature plot near the midpoint temperature (Figure 6). This effect was observed for all of the peptides, including the minimal peptide Min4, which binds very weakly with a $K_{\mathrm{D}}$ of $\sim 16 \mu \mathrm{M}$ and which barely contributes to the denaturation midpoint temperature. To measure this effect quantitatively, we fit the thermal dena- 


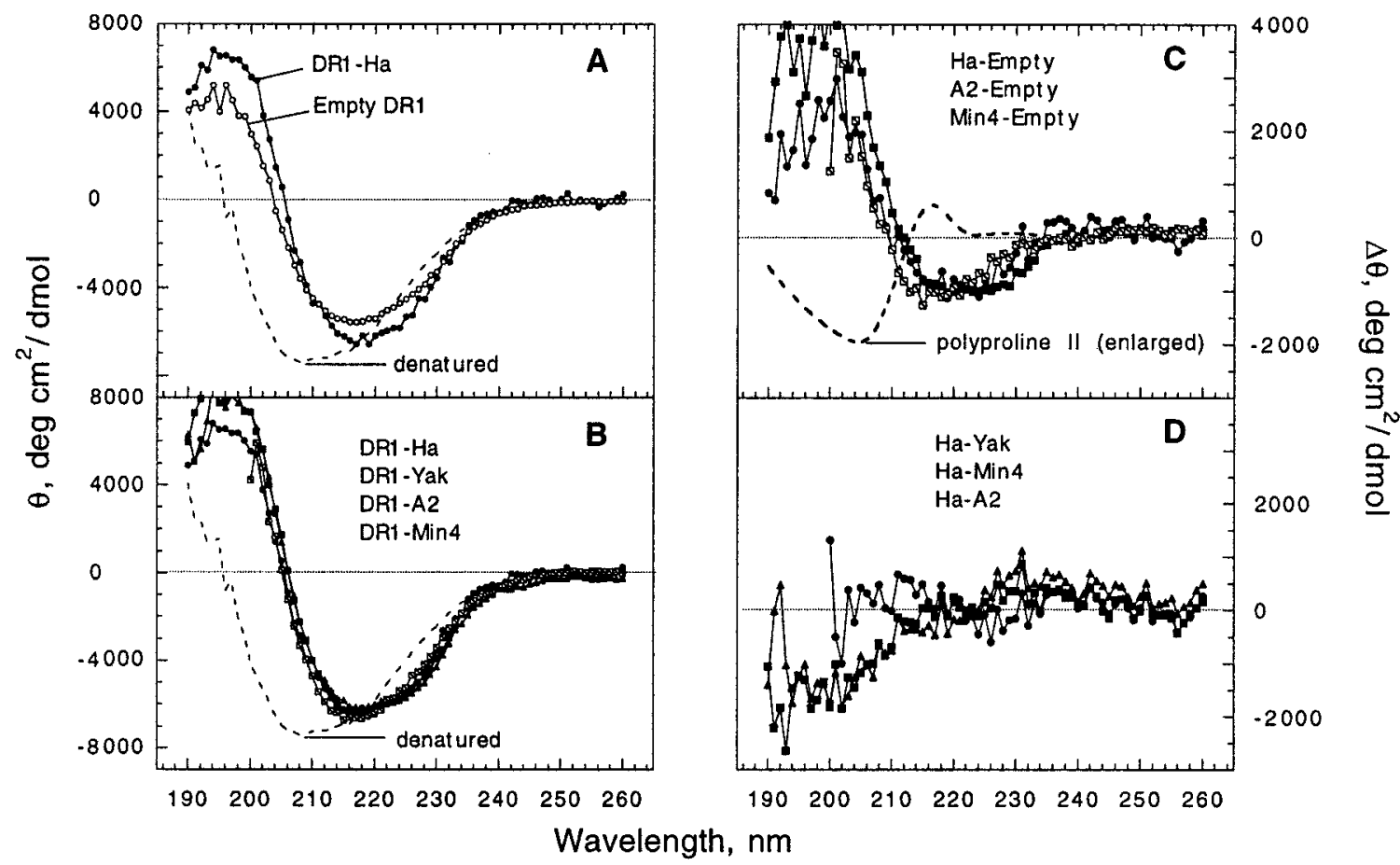

FIGURE 5: Peptide binding causes a change in the CD spectra of DR1. (A) Far-UV CD spectra for empty HLA-DR1 (O), the peptide

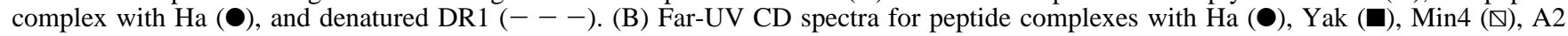

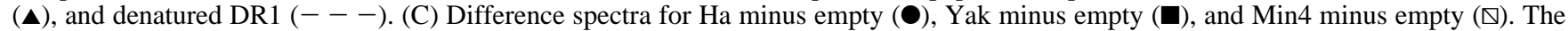
predicted spectrum for 13 residues of polyproline II helix $(---)$ is shown on an expanded scale (15×). (D) Difference spectra for Ha minus Min4 (๑), Ha minus Yak (ם), and Ha minus A2 (ム).

turation traces to a six-parameter equation with terms for the denaturation enthalpy $\Delta H_{\mathrm{v}}$, and the difference in heat capacity $\Delta C_{p}$ between the folded and unfolded states (see Experimental Procedures). The values for $\Delta H_{\mathrm{v}}$ increased upon peptide binding by $30-50 \mathrm{kcal} \mathrm{mol}^{-1}$ and for $\Delta C_{p}$ by 1.3-3.9 $\mathrm{kcal} \mathrm{mol}^{-1} \mathrm{~K}^{-1}$ (Table 2). These are large changes compared with those usually observed for simple binding of ligands to proteins, and indicate a global effect of peptide in increasing the number of interactions that stabilize the overall folded MHC structure. Such an increase in the number of interactions could occur if parts of the protein that do not interact with each other in the empty form do so after the peptide is bound.

Finally, we tested the reactivity of several monoclonal antibodies toward empty and peptide-loaded DR1, to determine if the conformation change could be localized to a particular region of the protein. The monoclonal antibody KL295 specifically reacts with empty DR1 and not with any of the peptide complexes (Figure 7). Several other antibodies showed little or no discrimination (data not shown). To exclude the possibility that an extended region of KL295 had bound as a peptide in the MHC peptide binding site, we tested denatured KL295, which did not bind to empty DR1 (Figure 7). Although the precise epitope for KL295 on DR1 has not been mapped, the antibody was raised against a peptide from the murine class II MHC protein I-A ${ }^{\mathrm{b}, \mathrm{d}}, \beta 59-$ 70, AEYWNSQPEILE (44), and likely recognizes the homologous region in DR1, $\beta 58-69$, AEYWNSKDLLE (changes underlined). This region (shaded in the inset of Figure 7 ) is in the helical part of the $\beta 1$ domain near peptide side chain binding pockets 7 and 9 (9). To demonstrate that the loss of KL295 reactivity with peptide-bound DR1 was due to a peptide-induced conformational change in DR1 rather than to a simple steric block of the KL295 epitope by the bound peptide, we tested the minimal tetrameric peptide Min4. Min4 most likely binds in pockets 1 and 4 (47), away from the KL295 epitope near pockets 7 and 9. The activity of Min4 in substantially blocking KL295 binding (Figure 7) demonstrates that the loss of KL295 reactivity with peptide binding is the result of the peptide-induced conformational change rather than the result of a direct steric block. KL295 can bind synthetic peptide corresponding to HLA-DR1 $\beta 58-$ 69 , which is unstructured in aqueous solution at room temperature (A. K. Sato and L. J. Stern, unpublished results). Selective KL295 reactivity with empty DR1 but not the peptide-loaded form suggests that in the intact empty protein, the $\beta 58-69$ region is largely unstructured, but folds during peptide binding to adopt a conformation not recognized by the antibody.

\section{DISCUSSION}

The results described above indicate that a distinct conformational change occurs upon peptide binding to HLADR1. The conformation change is observed with each of a number of peptides with very different sequences and affinities. The hydrodynamic parameters obtained via several methods indicate that the empty protein has a larger, less compact structure than the peptide-bound complexes, with an effective hydrodynamic radius that is approximately 10$15 \%$ greater. The empty protein also has reduced thermal stability and reduced unfolding cooperativity relative to the peptide-bound complexes, consistent with a looser conformation for the empty protein. All of the peptide-bound complexes, including that with the weakly binding tetrameric Min4 peptide, appear to have attained the compact form described by crystal structural analysis.

The magnitude of this hydrodynamic change is large for a simple ligand-binding reaction. Upon binding a ligand, 


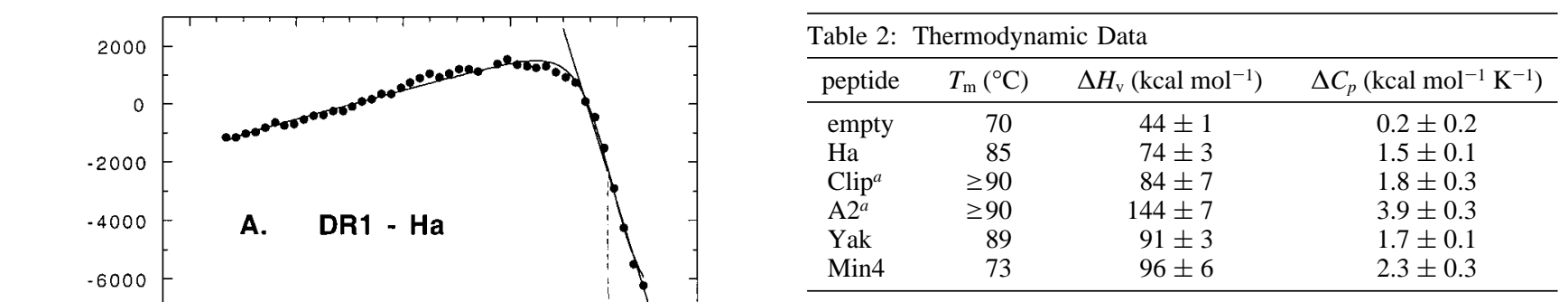

${ }^{a}$ Values for these complexes have greater experimental uncertainty because the high melting temperature limits collection of post-transition data.
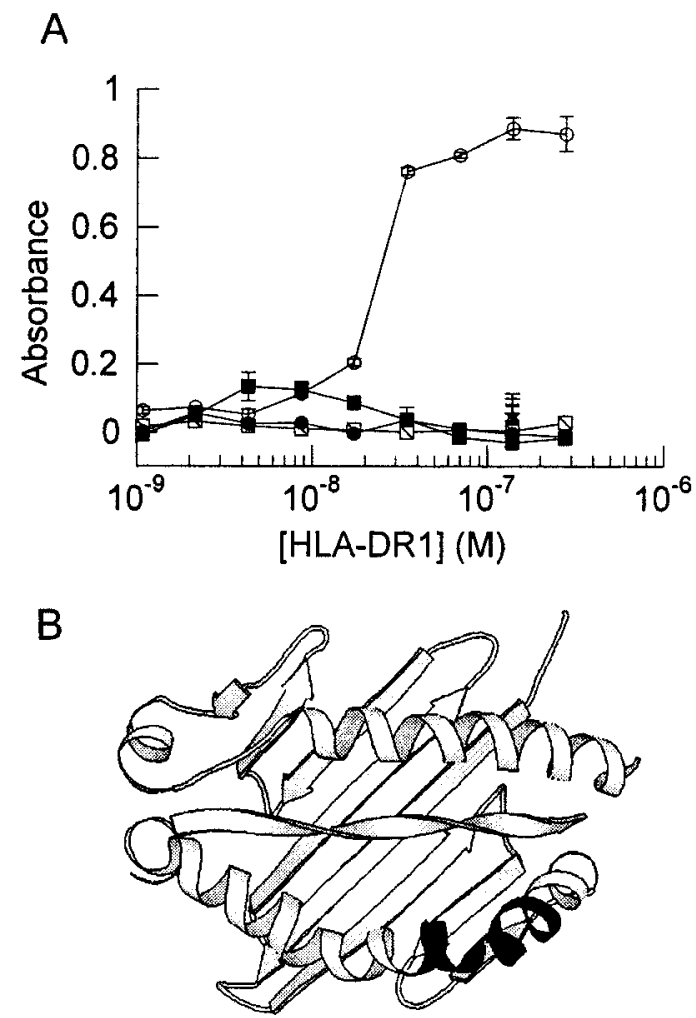

FIGURE 7: Monoclonal antibody KL295 distinguishes empty and peptide-loaded forms of HLA-DR1. (A) Sandwich ELISA using immobilized KL295 and anti-DR1 polyclonal serum. Empty DR1 (O) reacts with KL295, but the peptide complexes Ha (O), Yak $(\mathbf{\square})$, and Min4 $(\nabla)$ do not. Control experiments were performed at $1.5 \times 10^{-7} \mathrm{M}$ with denatured KL295 $(\times)$, mouse IgG (+), and BSA $(\triangle)$. (B) The putative KL295 peptide epitope (44) is highlighted in the ribbon diagram of the peptide binding site of DR1 (9).

binding. Little or no change is seen in the far-UV CD upon ligand binding, and the unliganded proteins are nearly as stable as the liganded form. In other cases that involve large ligand-induced hinge motions, such as 3-phosphoglycerate kinase (55), or for global conformational rearrangements, such as that of influenza hemagglutinin $(56,57)$, much larger changes in hydrodynamic and/or spectroscopic properties can be observed.

What structural changes might occur in DR1 upon binding a peptide that are responsible for the large change in hydrodynamic parameters? Partial local unfolding of particular regions in the absence of a peptide could provide an explanation. The empty protein does not appear to be largely unfolded, as judged by circular dichroism spectroscopy. Unfolding or substantial secondary structure alteration of 10-20 residues would be consistent with the magnitude of 
observed changes in the far-UV CD spectra $(58,59)$. One component of the overall peptide-induced conformational change involves the KL295 epitope $\beta 58-69$, which, upon peptide binding, appears to fold to a conformation that is not recognized by the peptide-specific antibody KL295. The $\mathrm{N}$-terminal half of this epitope (right in Figure 7B) in the class II MHC-peptide complex comprises the last turn of a short helix $(\beta 58-62)$ that makes several important contacts with the bound peptide but few contacts with the remainder of the MHC protein (9). The C-terminal half is a helical kink $(\beta 63-67)$ that does not contact the peptide or the $\beta$-sheet floor of the MHC protein. This latter segment exhibits high $B$-factors in the peptide complex crystal structures that are indicative of some flexibility or disorder $(9,10)$, and also is the site of a short insertion and/or frame shift in the murine homologue I-A (3). Thus, the KL295 epitope is relatively loosely constrained even in the presence of bound peptide, and may be largely unfolded in the empty protein. Could a local unfolding or unraveling of this region explain the observed hydrodynamic changes? Modeling studies indicate that, if fully extended, this region would add $\sim 8 \AA$ to the overall length of DR1 (76 $)$ ), possibly accounting for some or most of the observed change. The unraveled region might extend further along the helix. The ability of the short peptide Min4 to induce the conformation change suggests that the unfolded region might extend another turn along the helix to include the putative Min4 contacts in pocket 4 .

Another structural factor that might contribute to the peptide-induced conformational change may be a change in the interdomain interactions. In class II MHC proteins, the lower, immunoglobulin-like $\beta 2$ domain is docked onto the $\alpha 1 \beta 1$ peptide binding domain through an interaction between its top end and a depression formed underneath pocket 1 (5). Several residues in the binding site contact both the depression and pocket 1, and could communicate peptide binding changes to the lower domains. Similar peptidedependent domain alteration could occur between the $\alpha 2$ domain and the underside of the peptide binding site (5).

The conformational change that we observe here may have an important function in antigen presentation in that it can act to trap peptides within the peptide binding site. A trapping mechanism has been suggested by several kinetic studies which revealed a slow unimolecular conversion of a loosely bound intermediate state to the final stable complex $(19,20)$. We hypothesize that the conformational change observed here corresponds to the slow unimolecular conversion observed in kinetic studies, and provides a physical mechanism for the kinetic trap. In this model, the initial peptideMHC encounter complex still retains the empty conformation, and the slow kinetic step represents the conversion to the peptide-loaded form. Folding of all or part of the $\beta$-subunit helix could contribute substantially to this trapping mechanism. In the crystal structures, several residues from this region lie over the peptide, particularly in the region of pockets 4 and 7 (9). If these residues are in a different or unfolded conformation prior to peptide binding, the site would be accessible to peptide entry. Helix formation upon peptide binding could then physically occlude peptide release. The detailed mechanism by which the conformational change is triggered by initial peptide occupancy in the groove remains unclear, but the Min4 results suggest that interactions with residues in positions $1-4$ appear to be sufficient to trigger the change.

Several models for the activity of the peptide exchange factor HLA-DM in catalyzing peptide exchange postulate a loosely bound class II MHC-peptide complex intermediate that interacts with HLA-DM $(60-65)$. If the correspondence between the kinetic mechanism and the conformational change observed here is correct, the kinetic intermediate retaining the conformation of the empty protein provides a handle for recognition by HLA-DM. By preferentially binding the intermediate complex, HLA-DM would promote both dissociation and binding reactions. Although the $\beta 58-$ 68 region presents an attractive possible target for HLADM interaction, we have observed peptide-induced changes in other regions of the proteins, for example, the L243 discontinuous epitope (66) that includes Glno19, Met $\alpha 36$, and Lys $\alpha 38$ (A. K. Sato and J. A. Zarutskie, unpublished observations), and as noted above, the conformational change might also include domain motions that could be sensed by HLA-DM or other proteins.

The difference in conformation between empty and peptide-loaded DR1 could also play an important role in controlling the intracellular trafficking pathways of class II MHC proteins. Empty class II MHC proteins tend to aggregate, and in vivo, this aggregation has been shown to correlate with removal and/or degradation of endosomal class II MHC proteins that have not acquired peptide (67). Different conformations for empty and peptide-loaded MHC, with the empty conformation prone to aggregation, appear to provide the physical explanation for the ability of even weakly binding peptides to protect class II MHC proteins from aggregation both in vivo and in vitro. The conformational change may have yet another role in the poorly characterized process by which MHC proteins that have acquired bound peptide are released from the endosome and transported to the cell surface. In this scenario, class II MHC proteins in the peptide-bound state would specifically associate with novel trafficking factors that control export from the endosome.

In summary, we have shown by several physical methods that a distinct change in conformation accompanies peptide binding to the human class II MHC protein HLA-DR1. The extents of hydrodynamic, spectroscopic, and thermodynamic changes are consistent with local unfolding of a region including residues from $\beta 58-68$, which is the epitope for an anti-peptide antibody that specifically recognizes the empty protein, perhaps along with other changes. The conformational change traps peptides with widely varying sequences and affinities within the site for presentation to $\mathrm{T}$-cells, and may play a role in interacting with endosomal proteins controlling antigen presentation.

\section{ACKNOWLEDGMENT}

We thank Jonathan King and Scheherazade SadeghNasseri for helpful discussion, Marlene Bouvier for assistance with analysis of the thermal denaturation data, David Akey and Brian Schneider of the Kim group for their generous help with ultracentrifugation and circular dichroism equipment, Ravi Joshi and Jennifer Ogrodnick for their scientific advice and assistance, and Laura Santambroglio for help with the KL295 experiments. 


\section{REFERENCES}

1. Watts, C. (1997) Annu. Rev. Immunol. 15, 821-850.

2. Germain, R. (1994) Cell 76, 287-299.

3. Scott, C. A., Peterson, P. A., Teyton, L., and Wilson, I. A. (1998) Immunity 8, 319-329.

4. Fremont, D. G., Monnaie, D., Nelson, C. A., Hendrickson, W. A., and Unanue, E. (1998) Immunity 8, 305-317.

5. Murthy, V., and Stern, L. J. (1997) Structure 5, 1385-1396.

6. Dessen, A., Lawrence, C. M., Cupo, S., Zaller, D. M., and Wiley, D. C. (1997) Immunity 7, 473.

7. Fremont, D. H., Hendrickson, W. A., Marrack, P., and Kappler, J. (1996) Science 272, 1001-1004.

8. Ghosh, P., Amaya, M., Mellins, E., and Wiley, D. C. (1995) Nature 378, 457-462.

9. Stern, L. J., Brown, J. H., Jardetzky, T. S., Gorga, J. C., Urban, R. G., Strominger, J. L., and Wiley, D. C. (1994) Nature 368, 215-221.

10. Brown, J. H., Jardetzky, T. S., Gorga, J. S., Stern, L. J., Urban, R. G., Strominger, J. L., and Wiley, D. C. (1993) Nature 364, 33-39.

11. Sinigaglia, F., and Hammer, J. (1994) Curr. Opin. Immunol. $6,52-56$.

12. Dornmair, K., and McConnell, H. M. (1990) Proc. Natl. Acad. Sci. U.S.A. 87, 4134-4138.

13. Dornmair, K., Rothenhausler, B., and McConnell, H. M. (1989) Cold Spring Harbor Symp. Quant. Biol. 54, 409-416.

14. Sadegh-Nasseri, S., and Germain, R. N. (1991) Nature 353, $167-170$.

15. Bikoff, E. K., Huang, L.-Y., Episkopou, V., van Meerwijk, J., Germain, R. N., and Robertson, E. J. (1993) J. Exp. Med. 177, 1699-1712.

16. Viville, S., Neefjes, J., Lotteau, V., Dierich, A., Lemeur, M., Ploegh, H., Benoist, C., and Mathis, D. (1993) Cell 72, 635648.

17. Peterson, M., and Miller, J. (1990) Nature 345, 172-174.

18. Wettstein, D. A., Boniface, J. J., Reay, P. A., Schild, H., and Davis, M. M. (1991) J. Exp. Med. 174, 219-228.

19. Joshi, R., Zarutskie, J., and Stern, L. (1999) (manuscript in preparation).

20. Sadegh-Nasseri, S., and McConnell, H. M. (1989) Nature 337, 274-276.

21. Sadegh-Nasseri, S., Stern, L. J., Wiley, D. C., and Germain, R. N. (1994) Nature 370, 647-650.

22. Jensen, P. E. (1990) J. Exp. Med. 171, 1779.

23. Boniface, J., Lyons, D., Wettstein, D., Allbritton, N., and Davis, M. M. (1996) J. Exp. Med. 183, 119-126.

24. Runnels, H. A., Moore, J. C., and Jensen, P. E. (1996) J. Exp. Med. 183, 127-136.

25. Reich, Z., Altman, J. D., Boniface, J. J., Lyons, D. S., Kozono, H., Ogg, G., Morgan, C., and Davis, M. M. (1997) Proc. Natl. Acad. Sci. U.S.A. 94, 2495-2500.

26. Bouvier, M., and Wiley, D. C. (1998) Nat. Struct. Biol. 5, 377-383.

27. Bouvier, M., and Wiley, D. C. (1994) Science 265, 398-402.

28. Fahnestock, M. L., Tamir, I., Narhi, L., and Bjorkman, P. J. (1992) Science 258, 1658-1662.

29. Gorga, J. C., Dong, A., Manning, M. C., Woody, R. W., Caughey, W. S., and Strominger, J. L. (1989) Proc. Natl. Acad. Sci. U.S.A. 86, 2321-2325.

30. Stern, L. J., and Wiley, D. C. (1992) Cell 68, 465-477.

31. Frayser, M., Sato, A. K., Xu, L., and Stern, L. J. (1999) Protein Expression Purif. 15, 105-114.

32. Jensen, P. E., Moore, J. C., and Lukacher, A. E. (1998) J. Immunol. Methods 215, 71.

33. Roche, P. A., and Cresswell, P. (1990) J. Immunol. 144, 18491855.

34. Siegel, L. M., and Monty, K. J. (1966) Biochim. Biophys. Acta $112,346-362$.

35. Cantor, C. R., and Schimmel, P. R. (1980) Biophysical Chemistry, Vol. II, W. H. Freeman and Co., New York.

36. Braginskaya, T. G., Dobitchin, P. D., Ivanova, M. A., Klyubin, V. V., Lomakin, A. V., Noskin, V. A., Shmelev, G. E., and Tolpina, S. P. (1983) Phys. Scr. 28, 73-79.
37. Thomas, H. G., Lomakin, A., Blankschtein, D., and Benedek, G. B. (1997) Langmuir 13, 209-218.

38. Svedberg, T. (1925) Kolloid-Z. 36, 53.

39. Rabanal, F., Ludevid, M. D., Pons, M., and Giralt, E. (1993) Biopolymers 33, 1019-1028.

40. Sanchez-Ruiz, J. M. (1992) Biophys. J. 61, 921-935.

41. Privalov, P. L., and Gill, S. J. (1988) Adv. Protein Chem. 39, 193-234.

42. Becktel, J., and Schellman, J. A. (1987) Biopolymers 26, 1859-1877.

43. Creighton, T. E. (1993) Proteins: Structures and Molecular Properties, 2nd ed., W. H. Freeman and Co., New York.

44. Lapan, K. L., Klapper, D. G., and Frelinger, J. A. (1992) Hybridoma 11, 217-223.

45. Chicz, R. M., Urban, R. G., Lane, W. S., Gorga, J. C., Stern, L. J., Vignali, D. A. A., and Strominger, J. L. (1992) Nature $358,764-768$.

46. Jardetzky, T. S., Gorga, J. C., Busch, R., Rothbard, J., Strominger, J. L., and Wiley, D. C. (1990) EMBO J. 9, 17971803.

47. Hammer, J., Belunis, C., Bolin, D., Papdopoulos, J., Walsky, R., Higelin, J., Danho, W., Sinigaglia, F., and Nagy, Z. A. (1994) Proc. Natl. Acad. Sci. U.S.A. 91, 4456-4460.

48. Jacobsen, M. P., and Winzor, D. J. (1997) Prog. Colloid Polym. Sci. 107, 82-97.

49. Durchschlag, H., Zipper, P., Purr, G., and Jaenicke, R. (1996) Colloid Polym. Sci. 274, 117-137.

50. Harris, S. J., and Winzor, D. J. (1988) Arch. Biochem. Biophys. $265,458$.

51. Oberfelder, R. W., Barisas, B. G., and Lee, J. C. (1984) Biochemistry 23, 458.

52. Bennett, W. S., and Steitz, T. A. (1980) J. Mol. Biol. 140, 211

53. Smith, G. D., and Schachman, H. K. (1973) Biochemistry 12, 3789-3801.

54. Jaenicke, R., and Gratzer, W. B. (1969) Eur. J. Biochem. 10, $158-164$.

55. Roustan, C., Fattoum, A., Jeanneau, R., and Pradel, L.-A. (1980) Biochemistry 19, 5168-5175.

56. Ruigrok, R. W. H., Martin, S. R., Wharton, S. A., Skehel, J. J., Bayley, P. M., and Wiley, D. C. (1986) Virology 155, 484497.

57. Skehel, J. J., Bayley, P. M., Brown, E. B., Martin, S. R., Waterfield, M. D., White, J. M., Wilson, I. A., and Wiley, D. C. (1982) Proc. Natl. Acad. Sci. U.S.A. 79, 968-972.

58. Merelo, J. J., Andrade, M. A., Prieto, A., and Moran, F. (1994) Neurocomputing 6, 443-454.

59. Andrade, M. A., Chacon, P., Merelo, J. J., and Moran, F. (1993) Protein Eng. 6, 383-390.

60. Mosyak, L., Zaller, D. M., and Wiley, D. C. (1998) Immunity 9, 377-383.

61. Fremont, D. H., Crawford, F., Marrack, P., Hendrickson, W. A., and Kappler, J. (1998) Immunity 9, 385-393.

62. Kropshofer, H., Arndt, S. O., Moldenhauer, G., Hammerling, G. J., and Vogt, A. B. (1997) Immunity 6, 293-302.

63. Vogt, A. B., Kropshofer, H., Moldenhauer, G., and Hammerling, G. J. (1996) Proc. Natl. Acad. Sci. U.S.A. 93, 97249729.

64. Sloan, V. S., Cameron, P., Porter, G., Gammon, M., Amaya, M., Mellins, E., and Zaller, D. M. (1995) Nature 375, 802806.

65. Denzin, L. K., and Cresswell, P. (1995) Cell 82, 155-165.

66. Fu, X. T., and Karr, R. W. (1994) Hum. Immunol. 30, 253260

67. Germain, R. N., Castellino, F., Han, R., Reis e Sousa, C., Romagnoli, P., Sadegh-Nasseri, S., and Zhong, G.-M. (1996) Immunol. Rev. 151, 5-30.

BI983048M 